This is an author produced version of a paper published in Diseases of the Colon and Rectum. This paper has been peer-reviewed but does not include the final publisher proof-corrections or journal pagination.

Citation for the published paper:

Orno AK, Marsal K.

"Sonographic Investigation of the Rectoanal Inhibitory Reflex: A Qualitative Pilot Study in Healthy Women"

Diseases of the Colon and Rectum, 2005, Issue: Dec 8.

http://dx.doi.org/10.1007/s10350-005-0259-6

Access to the published version may require journal subscription.

Published with permission from: Springer 


\section{Sonographic investigation of the rectoanal inhibitory reflex, a qualitative Pilot study in healthy women}

Sonographic investigation of the rectoanal inhibitory reflex, a qualitative pilot study in healthy women

A.-K. Örnö, M. D. and K. Maršál, MD, PhD

Department of Obstetrics and Gynecology, Clinical Siences Lund, University of Lund, Sweden

Running title: Antiperistalsis in the anal canal

Meetings: 13th World Congress on Ultrasound in Obstetrics and Gynecology, Sep 1-5, 2003 Paris, France

Correspondence to: Ann-Kristin Örnö, M. D.

Department of Obstetrics and Gynaecology

University Hospital

S-221 85 LUND, Sweden

Phone: +46 46172551

Fax: +46 46157868

E-mail: ann-kristin.orno@med.lu.se

Reprints will not be available.

Hitachi Ultrasound Holding AG, Zug, Switzerland, provided the ultrasound scanner.

Keywords:

anal continence, anal incontinence, pelvic floor, ultrasound, rectoanal inhibitory reflex, internal anal sphincter 


\begin{abstract}
Purpose The rectoanal inhibitory reflex has been studied using various methods, e.g., anometry and electromyography. The aim of this study was to apply ultrasound for direct visualization of the rectoanal inhibitory reflex.

Method The rectoanal inhibitory was induced in ten healthy women (age 21-55 years) by injection of small amounts of water $(7,12$, and $20 \mathrm{ml})$, into the rectum. The intra-anal pressure was measured with a microtranducer and the rectoanal inhibitory reflex was visualized with real-time transvaginal or transperineal sonography.

Results The rectoanal inhibitory reflex consisted of a reduction in the intra-anal pressure and relaxation of the internal anal sphincter, manifested as an increase in the inner diameter of the internal anal sphincter from the mean of 11 to $16 \mathrm{~mm}(\mathrm{p}<0.001)$. Simultaneously, a wave of rectal contents entered the anal canal. The distance from the most distal border of the rectal contents to the anal verge decreased from mean 33 to $20 \mathrm{~mm}$ ( $\mathrm{p}<0.001)$. The rectoanal inhibitory reflex ended with a retrograde transport returning anal contents into the rectum. During the retrograde transport a contraction in the internal anal sphincter was observed. Conclusions The rectoanal inhibitory reflex can readily be visualized with ultrasound as a wave of rectal contents entering the anal canal. The transport into the anal canal was not of voluntary origin and could be either noticed or unnoticed by the subjects. The observed retrograde transportation in the anal canal was not noted by the subjects, related to a contraction in the internal anal sphincter and visualized for the first time using ultrasound. KEY WORDS: Rectoanal inhibitory reflex, anal continence, anal incontinence, internal anal sphincter, ultrasound.
\end{abstract}

\title{
INTRODUCTION
}

The rectoanal inhibitory reflex (RAIR), first described by Gowers in 1877, is considered an important contributor to anal continence. 1,2 The RAIR is defined as a response to rectal distension by relaxation of the anal canal that can be detected as a decrease in the intra-anal pressure. A decrease in electrical activity in the internal anal sphincter (IAS) and an increase in the external anal sphincter (EAS) have been measured.3-6 Relaxation of the anal canal occurs spontaneously about seven times per hour during long-term registrations.7 Experimentally, the RAIR has been elicited by gas, water, bolus, and electricity.8, 9 The RAIR can be refractory and is more pronounced in incontinent patients as compared to patients with chronic constipation and healthy subjects.10 Perineal and transvaginal ultrasound offers the possibility of a real-time dynamic scanning of the anal canal and visualization of the pelvic structures.11 Not only the sphincters and the longitudinal conjoined anal muscles, but also the rectal columns, the hemorrhoidal plexus, and the anorectum can be visualized.12,13 The aim of the study was to describe the RAIR using real-time transvaginal and transperineal sonography. 


\section{SUBJECTS AND METHOD}

The Research Ethics Committee at the University of Lund approved the study. Ten healthy female volunteers, with mean age of 38 years (range 21-55) gave their written informed consent. Six had given vaginal birth. None of them had had anal surgery, anal incontinence, or birth trauma. No sphincter tears were visible with perineal ultrasound. Five of the women were on hormonal contraceptives and two on hormone replacement therapy.

The investigation was performed on the subjects in the dorsal lithotomic position. No bowel preparation was given.

The RAIR was elicited three times by injections of 7,12 , and $20 \mathrm{ml}$ of water $\left(16^{\circ} \mathrm{C}\right)$, respectively, $90 \mathrm{~mm}$ proximal of the anal verge, through a plastic catheter (Ch 0.8$)$. The duration of the injection did not exceed three seconds. The anal pressure was measured by a microtransducer with a 1.2 mm diameter (Codman IPC, Microsensor Basic Kit ${ }^{\circledR}$, Johnson, Johnson, Raynham, MA, USA), inserted $20 \mathrm{~mm}$ into the anal canal. The position of the microtransducer was secured by a mark placed at the anal verge. The subjects were told to relax, not to squeeze voluntarily and to report sensations of pelvic fullness or urge. The RAIR was considered present when the intra-anal pressure dropped after an injection. The RAIR was monitored until the pressure increased to its initial level or to a new stable level. The anal canal was visualized in real-time using an ultrasound scanner with a $10 \mathrm{MHz}$ linear array transducer (Hitachi EUB-6500, Hitachi Tokyo Japan; transducer U553) placed in the vagina or on the perineum. The scans covering the sagittal plane of the anal canal from the rectum to the anal verge were recorded on videotape and magneto-optical disc. The RAIR was quantified off-line by measuring the changes in inner sagittal diameter of the IAS at puborectal level in the proximal anal canal and in distance from the most distal border of the rectal contents to the anal verge. Another four reflexes were studied using transverse transperineal scans.

Statistics

The results were evaluated using descriptive statistics and Student's t-test for paired observations. $\mathrm{P}<0.05$ was considered significant. The two first recorded reflexes in every subject were included in the statistical evaluation.

\section{RESULTS}

A total of thirty reflexes were induced, and 26 of these could be analyzed.

One injection did not give a reflex, in two cases gas coming from rectum made the measurements uncertain and in one case the microtransducer was out of order. The pressure decreased significantly during the reflex (Table1).

The mean time from injection until recovery to the original or a lower but stable pressure was 51 s (range 19-133s).

The landmark in transvaginal sonography is the hypoechogenic IAS seen as a ring or band around the hyperechogenic anal mucosa in transverse and longitudinal scans, respectively. The EAS, the puborectal muscle and the pubococcygeal muscle were identified as hyperechogenic structures. They were less well outlined against surrounding tissues except for the subcutaneous part of the EAS, which was seen caudal of the anal canal as a dropformed muscle with its acute angle anchored to the longitudinal muscle. The anal mucosa was recognized as a hyperechogenic zone filling the anal lumen. The anal canal and the surrounding muscles varied considerably in shape between the individuals (Figs. 1A and 2A). The reflex consisted of a minor wave of the rectal contents and injected water dilating the 
anorectum and the anal canal as far distally as to the EAS. This dilation gave a significant increase in the inner diameter of IAS in the most proximal part of the anal-canal (Table 1, Figs. 1B, 1C, 2B, and 2C). A relaxation in the puborectal muscle was observed before the maximal opening.

Thereafter, the muscles under the proximal anal canal were contracting in 11 out of 20 reflexes. The distance from the most distal edge of the rectal contents to the anal verge decreased significantly during the reflex (Table1).

In all the 26 elicited reflexes the opening of the anal canal was fast while the closing phase varied considerably in time. During the retrograde transport a thickening of the IAS was observed.

The subjects did not report the muscle actions as voluntary and experienced no urge. They reported a sensation of cold when the water was injected.

The rectal columns of the anal mucosa decreased in thickness during the reflex because of the dilation in the IAS. When the IAS contracted, the rectal columns filled the anal lumen.

\section{DISCUSSION}

Sonographic visualization of the anal canal can be used to describe and explain the events during the RAIR. To the best of our knowledge this is the first description of the RAIR using ultrasound. The muscle activity has previously been studied with electromyography and measurements of intra-anal pressure; real-time ultrasound imaging gives information about the relation between rectal and anal contents and about the effects of muscle relaxation and contractions. When examining children and men, perineal ultrasound can be used.11 We used cold water $\left(16^{\circ} \mathrm{C}\right)$, which is known to induce long and unstable reflexes9. This could probably explain why the duration of the RAIR varied so much. The long reflexes gave a more pronounced dilation of the anal canal thus making it more suitable for ultrasound study. During the recovery phase of these long reflexes the increase in anal pressure was interrupted by a new wave entering from the rectum lowering the pressure again. These waves might dilate the anal canal and must be seen as a preparation for defecation.14

The IAS together with the striated EAS is responsible for the resting pressure in the anal canal.3,4 There might also be a contribution from the conjoined longitudinal muscle but this has not yet been investigated.15 Using a proctoscope, Duthie and Benett, described an inflow of small amounts of rectal contents into the anal canal.16 This was named the sampling mechanism and explained as giving the subject information of the quality of the bolus, i.e., gas, liquid, or formed. Our investigation can confirm this inflow, it has not been related to rectal sensations or the discriminating properties in this study.

Goes et al. has shown that an increase in pressure after the RAIR starts in the high pressure zone in the distal anal canal and they concluded that this rise in pressure came from a contraction in the EAS.17 This is in agreement with our study since we observed a contraction in the striated muscles in 11 of 20 reflexes during the reflex recovery. The increase in pressure in the proximal part of the anal canal is dependent on a contraction in the IAS that propagates as an antiperistalsis in retrograde direction. 18. The retrograde transport in the anal canal, towards the peristalsis, can be involved in adaptation to larger quantities of contents in the rectum. Where the sensation of pelvic fullness or urge has its origin needs further investigation, but we agree with Broens et al. that the most probable location of the receptors is in or around the anal canal. These receptors are exposed to the rectal contents during the RAIR.19

The hemorrhoidal plexus did not fill the lumen in the proximal half of the anal canal when the relaxation occurred. Nevertheless, the rectal columns did not become flat during relaxation; 
instead they maintained much of their height which speaks in favor of an active process. The activity was mainly seen in the submucosa.20 What effect cold water might have on the anal mucosa is unclear.

In summary, during RAIR, the decrease of the intraanal pressure seems

to convey peristalsis by sending waves of rectal contents into the anal canal. The contraction of the IAS creates a retrograde transport in the anal canal, probably influencing the rectal storage capacity.

\section{ACKNOWLEDGMENTS}

The authors thank Lisa Bergin and Ann Thuring-Jönsson for technical support and encouragement.

\section{REFERENCES}

1. Sangwan YP, Coller JA. Fecal incontinence. Surg Clin North Am 1994;74:1377-98.

2. Gowers W. The Automatic Action of the Sphincter Ani. Proc R Soc Lond 1877;26:77-84.

3. Azpiroz F, Enck P, Whitehead WE. Anorectal functional testing: review of collective experience. Am J Gastroenterol 2002;97:232-40.

4. Sangwan YP, Solla JA. Internal anal sphincter: advances and insights. Dis Colon Rectum 1998;41:1297-311.

5. Zbar AP, Aslam M, Gold DM, Gatzen C, Gosling A, Kmiot WA. Parameters of the rectoanal inhibitory reflex in patients with idiopathic fecal incontinence and chronic constipation. Dis Colon Rectum 1998;41:200-8.

6. Rao SS. Pathophysiology of adult fecal incontinence. Gastroenterology. 2004;126(Suppl 1):14-22.

7. Miller R, Lewis GT, Bartolo DC, Cervero F, Mortensen NJ. Sensory discrimination and dynamic activity in the anorectum: evidence using a new ambulatory technique. Br J Surg 1988;75:1003-7.

8. Nagasaki A, Ikeda K, Sumitomo K. Rectoanal reflex induced by H2O thermal stimulation. Dis Colon Rectum 1989;32:765-8.

9. Gang Y. What is the desirable stimulus to induce the rectoanal inhibitory reflex? Dis Colon Rectum 1995;38:60-3.

10. Kaur G, Gardiner A, Duthie GS. Rectoanal reflex parameters in incontinence and constipation. Dis Colon Rectum 2002;45:928-33.

11. Beer-Gabel M, Teshler M, Barzilai N, et al. Dynamic transperineal ultrasound in the diagnosis of pelvic floor disorders: pilot study. Dis Colon rectum 2002;45:239-45.

12. Roche B, Deleaval J, Fransioli A, Marti MC. Comparison of transanal and external perineal ultrasonography. Eur Radiol 2001;11:1165-70.

13. Sultan AH, Loder PB, Bartram CI, Kamm MA, Hudson CN. Vaginal endosonography. New approach to image the undisturbed anal sphincter. Dis Colon Rectum 1994;37:1296-9. 14. Scharli AF, Kiesewetter WB. Defecation and continence: some new concepts. Dis Colon Rectum 1970;13:81-107.

15. Lunniss PJ, Phillips RK. Anatomy and function of the anal longitudinal muscle. Br J Surg 1992;79:882-4.

16. Duthie HL, Bennet RC. The relation of sensation in the anal canal to the functional anal 
sphincter: a possible factor in anal continence. Gut 1963;4:179-82

17. Goes RN, Simons AJ, Masri L, Beart RWJr. Gradient of pressure and time between proximal anal canal and high-pressure zone during internal anal sphincter relaxation. Its role in the fecal continence mechanism. Dis Colon Rectum 1995;38:1043-46.

18. Duthie HL, Watts JM. Contribution of external anal sphincter to the pressure zone in the anal canal. Gut 1965;6:64-8

19. Broens P, Vanbeckevoort D, Bellon E, Penninckx F. Combined radiologic and manometric study of rectal filling sensation. Dis Colon Rectum 2002;45:1016-22.

20. Gibbons CP, Trowbridge EA, Bannister JJ. Read NW. Role of anal cushions in maintaining continence. Lancet 1986;1:886-8.

\section{FIGURE LEGENDS}

Figure 1 (Figs. 1A, 1B, and 1C) Transvaginal sonogram of the anal canal in a sagittal section. $1 \mathrm{~A}$. At rest, the rectal contents (RC) are seen in the rectum. The internal anal sphincter (2) is contracted. The rectal columns (1) fill the lumen of the anal canal. Distance from the rectal contents to the anal verge (RD) 33mm. Diameter of the internal anal sphincter (ID) $10 \mathrm{~mm}$.

1B. During the rectoanal inhibitory reflex, the rectal contents (RC) are transported into the anal canal. The internal anal sphincter (2) is dilated. The rectal columns (1) outline the inside of the internal anal sphincter. Distance from the rectal contents to the anal verge (RD) $17 \mathrm{~mm}$. Diameter of the internal anal sphincter (ID) $16 \mathrm{~mm}$.

1C. Schematic explanatory drawing of the anal canal during the rectoanal inhibitory reflex. 1: Rectal columns (anal mucosa); 2: internal anal sphincter; 3: external anal sphincter; VW: vaginal wall; RC: rectal contents; ID: diameter of the IAS above the puborectal muscle; RD: distance from $\mathrm{RC}$ to anal verge.

Figure 2 (Figs. 2A, and 2B, and 2C) Transvaginal sonogram of the anal canal in a transverse section above the puborectal muscle.

2A. At rest, the rectal columns (1), held together by the internal anal sphincter

(2) seal the anal canal.

2B. During the rectoanal inhibitory reflex, rectal contents (RC) are seen in the anal canal. The internal anal sphincter (2) is dilated. The rectal columns (1) outline the internal anal sphincter. 2C. Schematic explanatory drawing of the proximal anal canal during the rectoanal inhibitory reflex.

1: Rectal columns (anal mucosa); 2: internal anal sphincter; PR: puborectal muscle; RC: rectal contents.

Table 1. Measurements during the rectoanal inhibitory reflex (RAIR) in 10 healthy women (means \pm SD).

Measurements Significance of at rest during RAIR difference (p)

Intra-anal pressure (mmHg)

$45.0 \pm 11.7$

$25.5 \pm 8.4$ 
$<0.001$

Diameter of the internal anal sphincter (mm)

$10.2 \pm 2.9$

$14.1 \pm 3.3$

$<0.001$

Distance rectal contents - anus (mm)

$33.6 \pm 3.6$

$21.9 \pm 5.5$

$<0.001$

RAIR : Rectoanal inhibitory reflex 


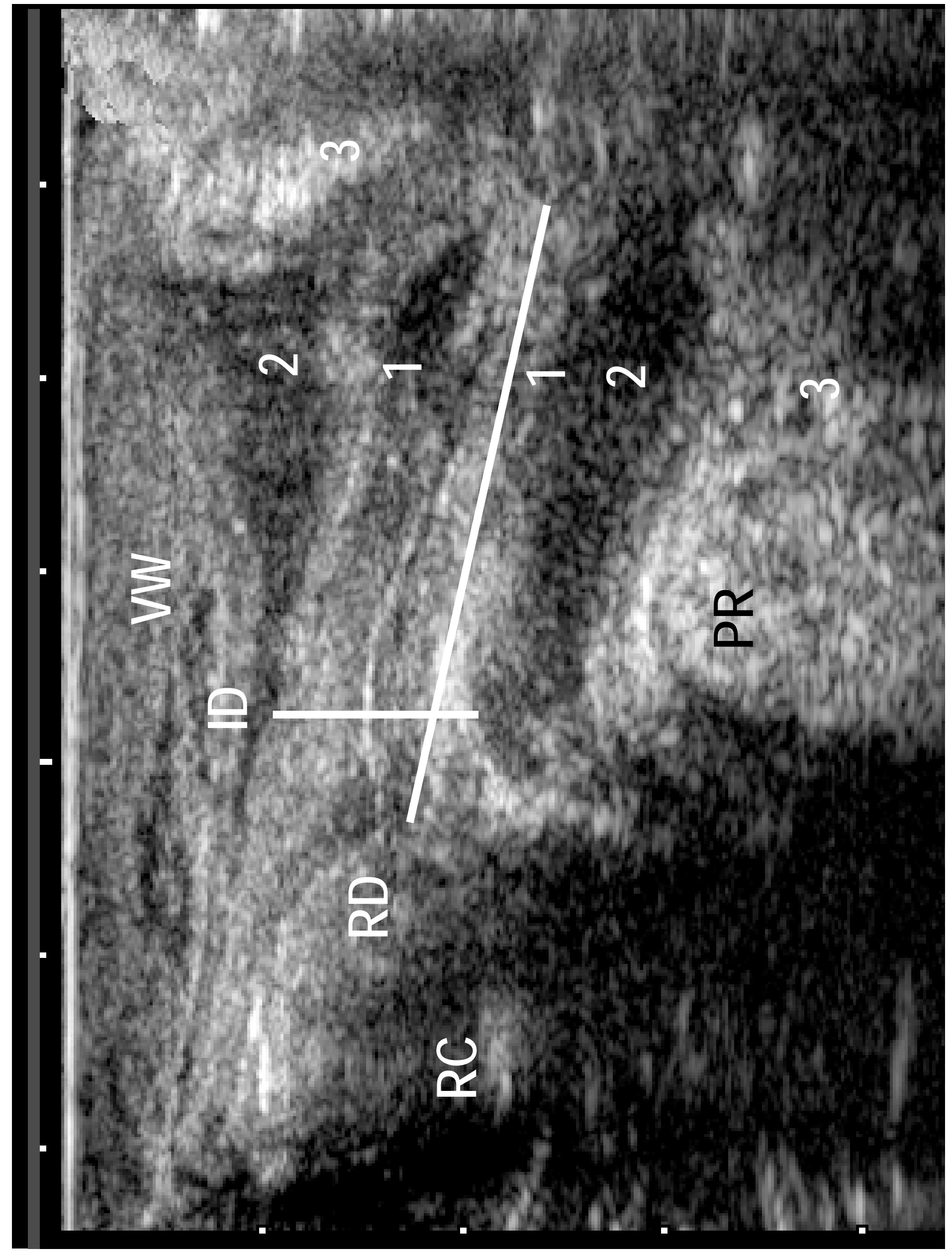




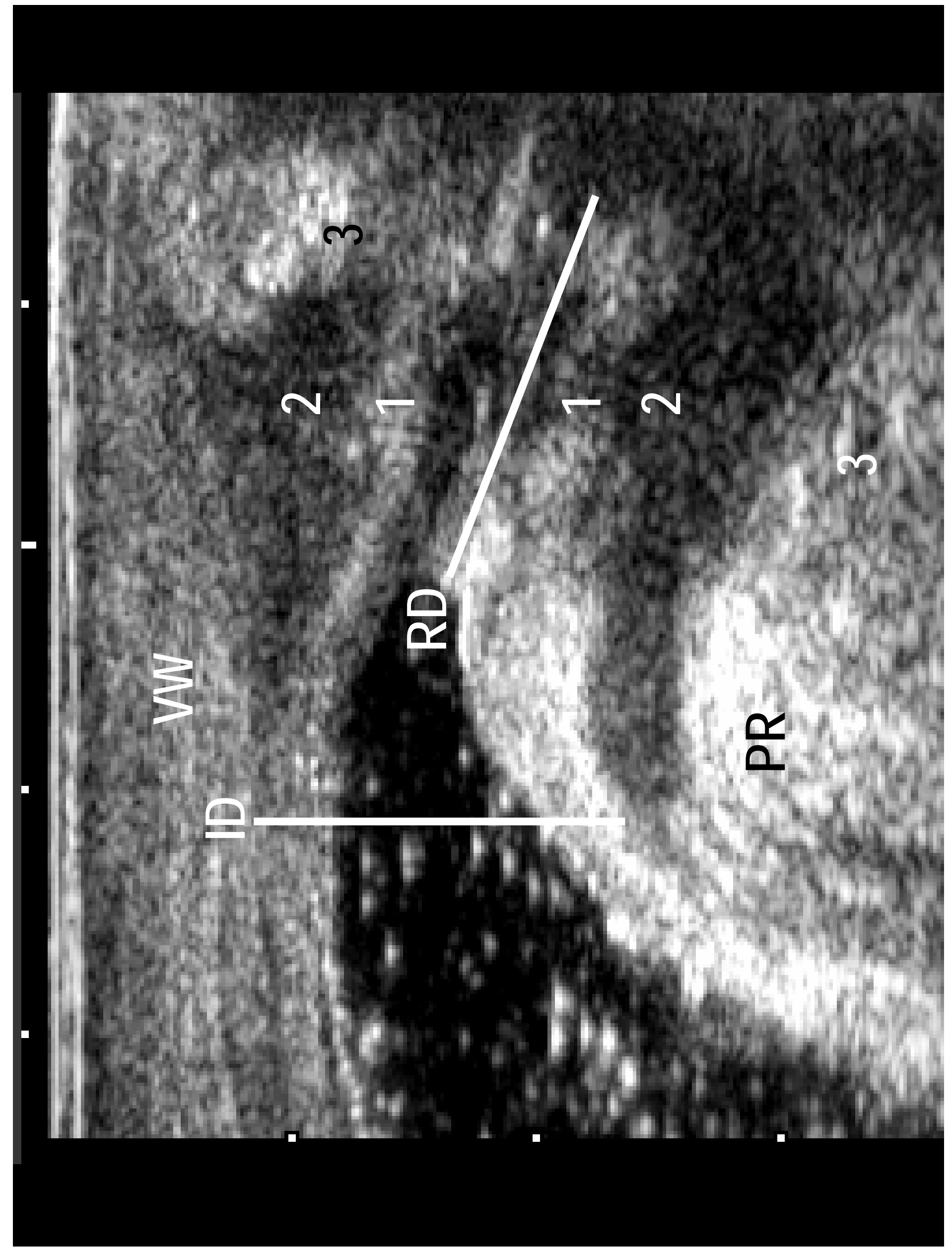




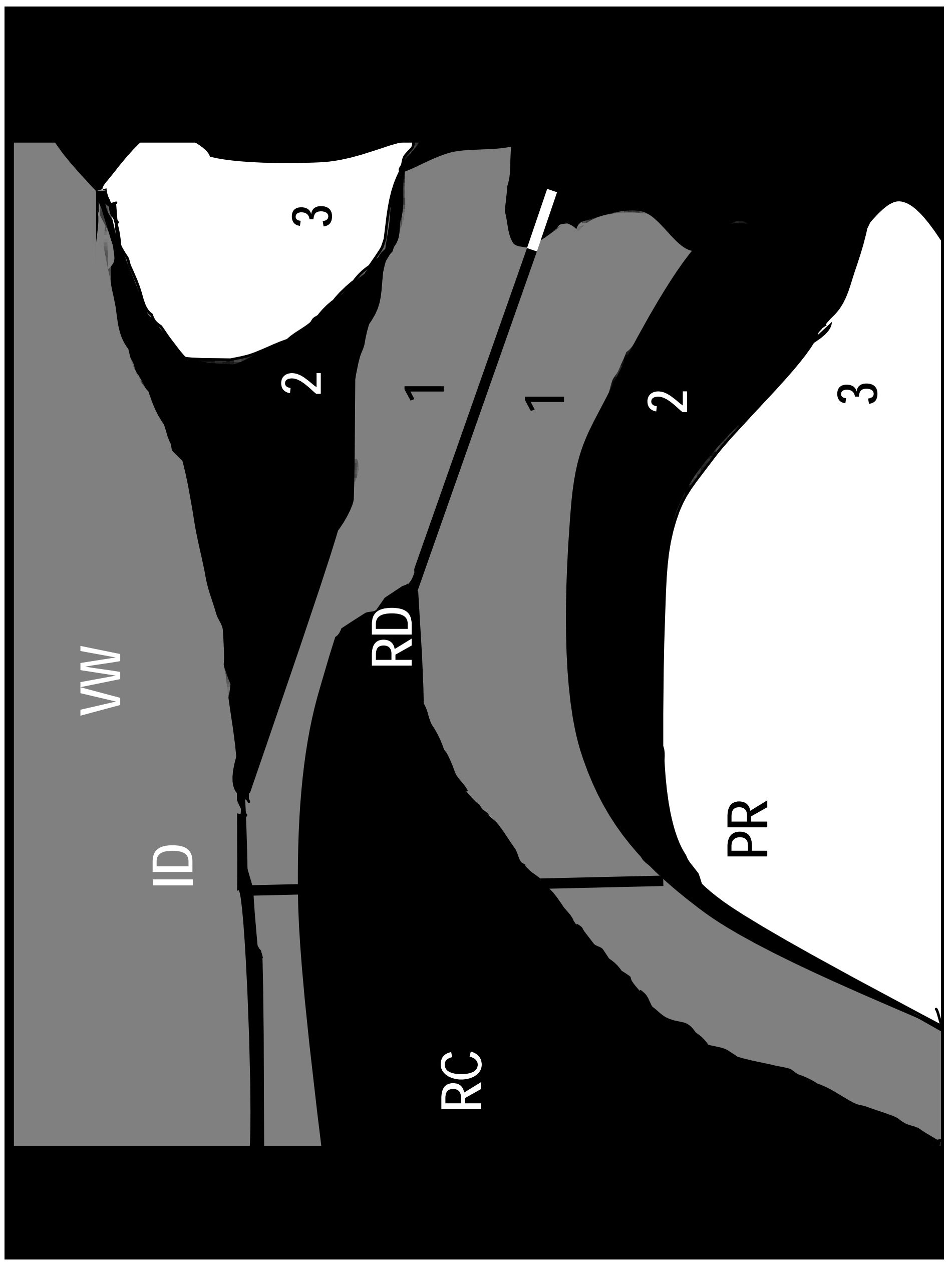




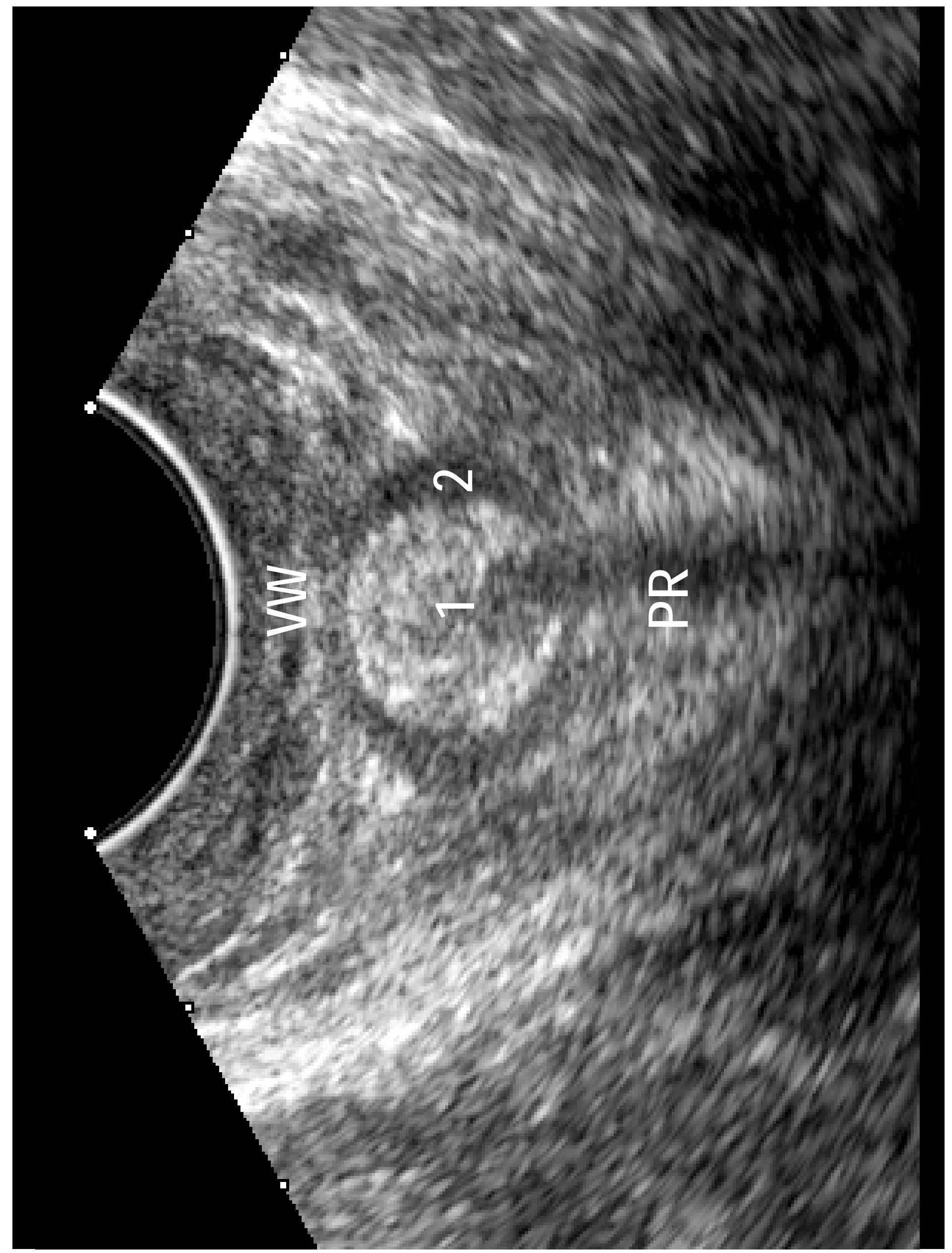




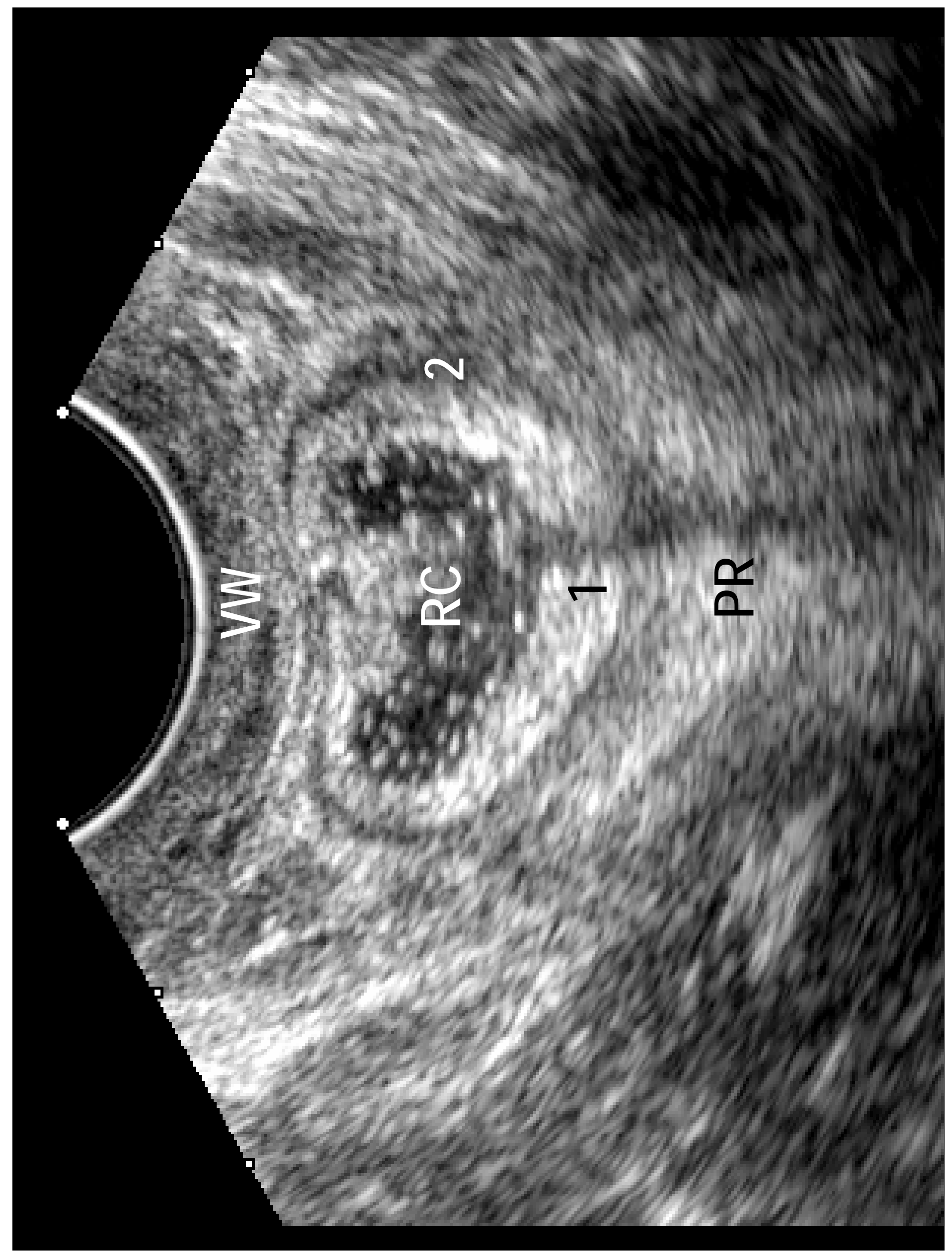




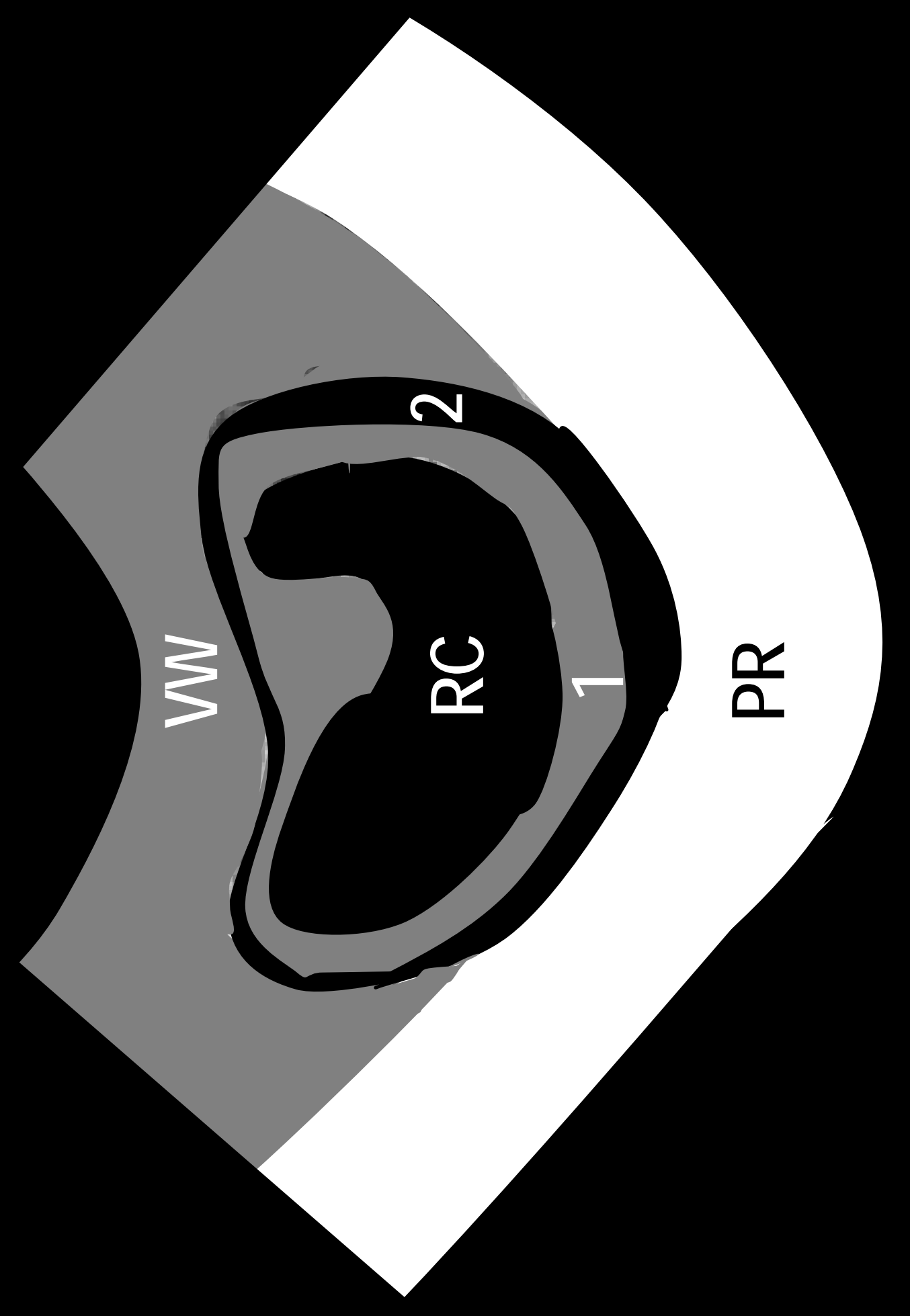

